\title{
The Correlation between Old and New Linguistic Paradigms: A Literature Review Based on Kuhn's School of Thoughts
}

\author{
Hanan Sarhan Alsubaiai ${ }^{1,2}$ \\ ${ }^{1}$ Department of English, Faculty of Languages and Translation, King Khalid University, Abha, Saudi Arabia \\ ${ }^{2}$ Department of English, College of Arts, University of Bisha, Bisha, Saudi Arabia \\ Correspondence: Hanan Sarhan Alsubaiai, Department of English, Faculty of Languages and Translation, King \\ Khalid University, Abha, Saudi Arabia \& Department of English, College of Arts, University of Bisha, Bisha, \\ Saudi Arabia.
}

Received: September 6, 2021

Accepted: September 22, 2021

Online Published: September 26, 2021

doi: 10.5539/elt.v14n10p84

URL: https://doi.org/10.5539/elt.v14n10p84

\begin{abstract}
This study aims to assess the evidence regarding the relationship between previous and new schools of linguistics. According to Kuhn (1970), old linguistic paradigms incorporate vocabulary and apparatus from previous or traditional paradigms. In particular, this review addresses the Question: Do new paradigms in linguistic arise from old or previous ones, as Kuhn suggested? The study is significant in understanding emerging schools of linguistics based on previous ones. A qualitative literature review was applied to compare new and old schools of linguistics. According to the findings, there is substantial evidence that functionalism, structuralism, and Transformational-Generative Grammar support Kuhn's argument. Most notably, the changes of the transformational-generative grammar from a consistent and straightforward Standard Theory to an improved Extended Standard Theory, and finally, to the Minimalist Program, point towards the same conclusion. Interestingly, the transformations demonstrate how new paradigms arise from old paradigms without borrowing many concepts, terms, and experiments from them. This study draws the attention of linguists in the $21^{\text {st }}$ Century to pay closer attention to the trends in schools of linguistics.
\end{abstract}

Keywords: extended standard theory, functionalism, linguistics, school of linguistics, standard theory, structuralism, transformational-generative grammar

\section{Introduction}

Schools of linguistics present a widely researched field in literature. Notably, various linguists subscribe to multiple theories and schools of thought that differ in how they define the inter-relationships between ideas, concepts, and terms. Since new paradigms emerge from old ones, Kuhn (1970) observed that they typically contain much of the vocabulary and apparatus, both conceptual and manipulating, that the conventional paradigm had previously utilized. However, they rarely use these borrowed components in the conventional sense. Old terminology, concepts, and experiments fall into a new connection with one another under the new paradigm.

With reference to Kuhn's argument, it is worth noting how functionalism emerged during the $19^{\text {th }}$ Century and became a famous school of linguistic that explained how scholars defined, researched, and taught linguistic theories and concepts. Comparatively, structuralism by Ferdinand de Saussure and generative grammar by Noam Chomsky were popular during different periods of the $20^{\text {th }}$ Century. Interestingly, Chomsky's school of linguistics underwent numerous drastic changes and improvements throughout the second half of the $20^{\text {th }}$ Century. For example, the original Transformational-Generative Grammar morphed into Standard Theory, Extended Standard Theory, and several other improved versions that defined the school of linguistics in the late $20^{\text {th }}$ Century. In contrast, functionalism and structuralism remained constant over time despite numerous criticism that both schools failed to accommodate new changes. As such, the most critical question is whether the gradual improvements associated with Chomsky's generative grammar make the school of linguistics better and more applicable than other schools.

Interestingly, the first part of Kuhn's statement demonstrates how previous schools of linguistics are developed from old ones. While the information may explain the transformations in Chomsky's generative grammar, it is unclear whether Kuhn's argument justifies functionalism and structuralism. As such, a thorough analysis of 
linguistic schools of thought is necessary for determining the correctness and relevance of Kuhn's statement. Significantly, Kuhn (1970) makes yet another bold claim that the new paradigms seldom employ these borrowed elements traditionally. This statement seems to contradict the three selected schools of linguistic. Therefore, there is a need to address the contradiction by comparing the three schools of linguistics and the well-defined improvements of generative grammar.

\section{Literature Review}

A review of literature provides crucial insights regarding functionalism, structuralism, and generative transformational grammar. Notably, functional linguistics is a broad school of linguistics that emerged in the early $19^{\text {th }}$ Century. Structuralism is another school of linguists during the mid- $20^{\text {th }}$ Century followed by a series of improved versions associated with Transformational-Generative Grammar. As such, this chapter presents a thorough comparative analysis of the selected schools of linguistics. The review of the literature shows the link between the three schools of thought based on Kuhn's argument.

\section{Functionalism}

Functional linguistics was supported by American scholars including William James and James Rowland Angell. Functionalism, according to Bates et al. (1991), is the view that natural language forms are generated, regulated, restricted, acquired, and utilized in the service of communication functions. Functional linguists tend to separate function from a structure of a particular language; thus, functionalism is ideal in explaining how people use language in their daily interactions. In this case, language becomes just one of the tools people use to communicate and interact (Christie, 2004). In particular, functionalists focus on a specific language's semantic, phonological, syntactic, and pragmatic functions. Outstandingly, functionalism is ideal for explaining the importance of the social context and the communicative process of phonology, grammar, and orthography of a particular language. However, Bates et al. (1991) noted that functionalism as a school of thought in linguistics had witnessed notable changes. For example, the term functionalism has increasingly lost its significance in communicating well. Therefore, according to Bates et al. (1991), functionalism means different things depending on the context in which people interact and use a particular language.

It is essential to consider the uniqueness of specific contexts in that; language is used to appreciate the significance of functionalism in understanding language (Qi, 2014, p. 115). For example, Bates et al. (1991) and Aslanova (2019) focused on the functionalists' approach to language and the implication for intervention and assessment with the medical setting. There is a notable yet constant tension between linguistic scholars in the speech-language pathology field regarding the best approaches to studying a language (Bates et al., 1991; Aslanova, 2019). In contrast, Christie (2004) and Almurashi (2016) explored the applicability of systemic functional linguistics, a theory derived from functionalism in applied linguistics. According to Christie (2004), systemic functional linguistics is limited since it fails to distinguish between applied and theoretical interests clearly. Therefore, linguistic scholars emphasize the need to use or apply carefully designed and controlled conditions when studying languages (Christie, 2004; Epçaçan, 2014; Almurashi, 2016). In contrast, medical professionals followed the clinical approach to identify ways to remediate language disorders as far as language use is concerned (Bates et al., 1991).

\section{Structuralism}

Structuralism is based on the argument that languages are fixed systems where different units connect. Studies by Al Umman (2015) and Ghosh (2016) explored the role of de Saussure and his role in shaping modern linguistics through structuralism. According to both studies, de Saussure became a notable figure for presenting functionalism as a 'new' school of linguistics that differed from historical linguistics. Structuralism marked a shift from a historical analysis of linguistics to a non-historical approach (Canagarajah, 2018). However, decades later, linguistic scholars started viewing structuralism as an outdated school of thought with little or no significance to the new changes in linguistics (Östman et al., 2007; Hussein \& Abushihab, 2014; Moghaddas \& Dekhnich, 2015; Muhammadi, 2016). Although structuralism works for morphology and phonology, many scholars, including Östman et al. (2007) and Hussein and Abushihab (2014), agree that it no longer makes as much sense as improved or newly proposed schools of linguistics. For example, as the founder of structuralism, de Saussure admitted his limited understanding of how the human brain works. Therefore, as Gastaldi and Pellissier (2020) reported, de Saussure agreed that future linguists were better positioned to formulate a more accurate and applicable linguistic school of thought or theory. However, Östman et al. (2007) demonstrated how general principles unite structuralism and other schools of linguistic that developed from it after World War 1. Östman et al. (2007) further noted how various linguists interpreted the same principles differently depending on the degree to which they supported de Saussure's version of structuralism. 
First, structuralism supports the idea of studying languages as systems. Therefore, the relationships that constitute a particular language system will always prioritize the specific linguistic units they generate (Östman et al., 2007). Most notably, functionalism is regarded as a radical rejection of atomism associated with the Neogrammarians, a famous linguistic school during the second half of the $19^{\text {th }}$ Century. While functionalism supports the language system, Neogrammarian supports the idiolect approach to linguistic investigation.

Second, structuralism is a unique school of linguistic considering how language changes over time. According to structuralism, a language should first be investigated from a synchronic viewpoint instead of a diachronic one since the latter depends on the former (Östman et al., 2007). However, many scholars agree that de Saussure's structuralism was not purely original and that he borrowed concepts from previous schools of linguistics (Hussein \& Abushihab, 2014; Moghaddas \& Dekhnich, 2015; Muhammadi, 2016). According to Moghaddas and Dekhnich (2015), structuralism backs the idea that language is a sophisticated system with distinct, interrelated parts. Importantly, Moghaddas and Dekhnich (2015) demonstrated how human activities and the resulting outcomes are constructed according to structuralism. As such, the notion of building new paradigms from old ones, as Kuhn (1970) argued, is evident when linguists apply structuralism.

Significantly, structuralism is based on the idea that systems, which define languages tend to have distinct structures. Therefore, it is through specific linguistic structures that newer or better paradigms are born from pre-existing ones. For example, as Moghaddas and Dekhnich (2015) and Muhammadi (2016) demonstrated, language studies before adopting structuralism were limited to syntactic, historical, and etymological aspects. However, in line with Kuhn's line of thought, Saussure introduced an entirely new attitude towards linguistic approaches. It is worth noting that Saussure was regarded as a pioneer of structuralism, and he focused on relating a particular language with the realities facing those who use it (Moghaddas \& Dekhnich, 2015). Hence, structuralism, as a school of linguistics, supports Kuhn's (1970) main idea on the close links between old and newer paradigms. However, exploring structuralism in isolation is not enough to clearly understand Kuhn's argument. Instead, a comparative analysis involving other schools of linguistics is needed to show the correlation between old and new paradigms. Instead, a comparison of structuralism with more recent and older schools of linguistics offers the much-needed platform to understand and appraise the correctness and applicability of other vital points that Kuhn makes.

\section{Transformational-Generative Grammar}

Transformational-Generative grammar is a notable linguistic school adopted in the mid-20 ${ }^{\text {th }}$ Century to explain how human beings acquire language and use it to communicate in different contexts. The school of linguistics is based on Noam Chomsky's work, an American linguist who argued that grammar is a system of rules. Therefore, according to the generativist approach, specific rules make a language in its most basic form. According to Chomsky, such laws end up forming grammatical sentences within a particular language. Most significantly, these rules apply not only in all languages but also to all members of the human race.

In this study, Transformational-generative grammar presents an insightful model that shows the complex interaction of rules and lexical entries. Through complex interactions, the structure of phrases associated with a particular language is linked to meaning. Morphology is a valuable concept that can help in explaining Kuhn's argument that new paradigms tend to incorporate much of the vocabulary and apparatus old ones. In linguistics, morphology refers to forming new words and relationships with other words in the same language. As such, Kuhn's argument is agreeable based on how new words emerge from new ones through morphology. In particular, the aspect of morphology that brings what Kuhn refers to as "conceptual and manipulative" means of incorporating old vocabulary and apparatus to form new paradigms. However, a study by Bagha (2011) reveals how generative semantics by linguists such as John R. Rose and George Lakoff stood mainly in opposition to Chomsky's transformational generative grammar. Interestingly, the same linguists developed the generative semantic model from Chomsky's work. Hence, as Kuhn suggests, the idea of creating new paradigms from old ones is evident in this case.

Chomsky's original version suggested that syntax is relatively autonomous concerning semantics. Contrastingly, proponents of linguistic semantics were keen on creating a more accommodative model that goes beyond Chomsky's interpretation of grammar as deep structures and accommodates a more detailed and complex underlying platform for explaining a higher level of synonymity Chomsky failed to address. According to Bagha (2011), generative semantics is unique in how it directly manages or accounts for meaning without syntactic structure. As such, generative semantics begins with a deep system, according to Chomsky, that is also pragmatic to some extent. Most significantly, semantic linguists account for all possible cases of synonymity in terms of the resulting intuitive structure. However, Kuhn's ideas become evident when transformations in a particular language define the form of a specific sentence. For example, a combination of semantic features and 
systems transforms through a deep design in a language, according to Brekle and Luelsdorff (1975). This combination ultimately yields or forms surface structures as Chomsky initially described as part of the original Standard Theory.

A closer examination of improved versions of generative grammar demonstrates that Chomsky initiated a long journey of developing and transforming the original generative model. Most significantly, the contribution of other linguistics, especially critics, contributed substantially to a series of changes adopted to address the shortcomings of the previous models. Notably, the original generative grammar model developed in 1965 underwent a series of transformations and adjustments to improve it and make it relevant based on the ever-changing realities in linguistics. The Transformational-Generative Grammar model, in particular, pulls together a number of later variants, including the Standard Theory, Extended Standard Theory, Revised Extended Standard Theory, Principles and Parameters Theory, Government and Binding Theory, Minimalist Program, and others. To examine Kuhn's argument's correctness and applicability, an examination of the Standard Theory, Extended Standard Theory, and Minimalist Program is contrasted.

As a school of linguistics, generative grammar can be traced back to 1965 when Chomsky proposed the Standard Theory. Nilsen (1987) described the original model as "...simple, complete, internally consistent, and rule-governed" (p. 243). However, since its inception, the generative transformational grammar had a syntactical bias that linguists criticized. Therefore, according to Nilsen (1987), various linguists took Chomsky's model in a different direction to address the shortcomings of Chomsky's original model. As Langendoen (1978) observed, the Standard Theory is based on the assumption that "the semantic interpretation of a sentence depends only on its lexical items and the grammatical functions" (p. 271). In addition, the Standard Theory was based on the apparent distinction between the surface and deep structures of a particular sentence, also known as the Aspects of the Theory of Syntax (Langendoen, 1978). According to Chomsky (1965), deep structure refers to thoughts, feelings, and concepts.

In contrast, the surface structure is the language, especially words used to represent the deep structure. This explains the familiar feeling that words are not enough to express oneself or bring out what is in mind. As such, deep structure represents what a person wants or wishes to communicate, while the surface structure is how they express it.

The Extended Standard Theory (EST) was closely followed during the late 1960s and early 1970s to improve the Standard Theory. This version focused on syntactic constraints and generalized phrase structures under the X-bar Theory, a theory of syntax. According to the X-bar Theory, every single phrase in every sentence in the cognitive grammar in every particular human language has the same core organization. Therefore, the shift from Chomsky's original theory to the Extended Standard Theory indicates that new paradigms arise from old ones, as Kuhn argued. In particular, the Extended Standard Theory strengthens what Chomsky's hypothesized regarding the autonomy of syntax. As noted by Langendoen (1978), the EST is an improvement of the ST since the "...scope of logical elements and quantifiers, co-reference, focus and certain kinds of presupposition, and certain other properties, are determined by rules that take surface structure into account" (p. 271). However, the idea of deep structures and surface structures of sentences remained the same. In this case, it is Chomsky who proposed the changes. About Kuhn's argument, it is clear that Chomsky developed the EST as a new paradigm by adopting ideas from the initial Standard Theory. Notably, Davies and Dubinsky (2004) show how the Extended Standard Theory brings filters and control to address the limitations of previous models. In similar studies, Alduais (2015) and Adetuyi and Fidelis (2015) investigated the base components that bring together improved versions of Transformational-Generative Grammar. According to Alduais (2015), the deep structures of sentences lead to transformations or transformational rules, which, in turn, advance to surface structures.

The Minimalist Program (MP) is the latest school of linguists developed that adopts the original Standard Theory by Chomsky. Broekhuis and Woolford (2013) noted that the MP is not necessarily a theory but a program. As such, the program brings together a set of approaches to reduce syntax or grammar to its absolute minimum. Notably, the Minimalist Program establishes a distinction between substantive and methodological. On the one hand, methodological minimalism defines a particular theory of language under construction (Al-Horais, 2013).

On the other hand, the substantive facet of the Minimalist Program is concerned with how well a particular language is designed (Johnson \& Lappin, 1997; Andreu \& Gallego, 2009). The Minimalist Program is a unique paradigm that functions as a mode of inquiry that approaches universal grammar from below. In other words, the Minimalist Program seeks the optimal answer to what Transformational Grammar should be. For example, Al-Horais (2013) noted how the program is based on the assumption that children come with biologically equipped principles of grammar construction referred to as Universal Grammar. 


\section{Critical Analysis}

A comparative analysis of functionalism, structuralism, and generative grammar reveals that new paradigms arise from old ones in line with Kuhn's argument, as mentioned above. It is evident how Chomsky's idea of transformational grammar contradicts earlier tenets of structuralism. In particular, the transformational-generative grammar approach rejects the notion associated with structuralism that every language is somehow unique. As noted by Chomsky (1965), linguists "...must consider the interaction of a variety of factors, of which the underlying competence of the speaker-hearer is only one" as the best approach to studying actual linguistic performance (p. 4). Chomsky's statement echoes Kuhn's argument that "within the new paradigm, old terms, concepts, and experiments fall into a new relationship" (p. 149).

Chomsky was keen on acknowledging various historical antecedents. Such historical antecedents played a crucial role in determining the application and relevance of a particular linguistic school. For example, the early versions of Chomsky's school of linguistics were based on transformational grammar. As the studies by Alduais (2003) and Davies and Dubinsky (2004) demonstrate, the term generative grammar is still used as a general term. As such, Kuhn was relatively accurate when he linked new paradigms with old ones. Notably, Chomsky acknowledged earlier linguistic schools and their foundational roles in developing even better and more applicable versions compared to original ones. For example, Chomsky noted how Panini's Sanskrit grammar was the first generative grammar in the modern sense. The numerous models associated with Chomsky's Transformational-Generative Grammar are somehow connected to the previous school of thought. In other words, they support Kuhn's idea of how new models came from older models with similar or closely related rules.

From the analysis above, it is clear how functionalism also supports Kuhn's argument by showing how new schools of linguistics arise to address the same issues that previous linguists were addressing. Bates et al. (1991) noted that functionalism had witnessed notable changes over the years, and the changes mirror Chomsky's Transformational-Generative Grammar. In both cases, Kuhn's ideas are evident, considering how new models rise from older ones. However, as Bates et al. (2006) noted, functionalism has increasingly lost its significance due to the ever-changing context in which people interact and use a particular language - as such, understanding the applicability of functionalism in comparison to other schools of linguistic is crucial considering the new realities in the $21^{\text {st }}$ Century. Compared to other schools of linguistics, including structuralism and Transformational-Generative Grammar, functionalism offers limited support for Kuhn's argument that new paradigms arise from old ones.

Similarly, structuralism supports the idea of language as a sophisticated system with distinct, interrelated parts, as the study by Moghaddas and Dekhnich (2015) demonstrated. The evidence on structuralism also shows how human activities and the outcomes of such actions are constructed in line with the structuralism school of thought. The whole idea of building new paradigms from old ones is evident. Therefore, Kuhn's (1970) argument is acceptable considering how structuralism works as a school of linguistics. In the same vein, systems tend to have distinct structures according to structuralism. As such, through specific linguistic structures presented in structuralism, newer or better paradigms arise from old ones. However, in line with Kuhn's argument, proponents of structuralism introduced and advocated for an entirely new attitude towards linguistic approaches. In particular, Saussure, a notable proponent of structuralism, focused on relating one specific language with the experiences of those who use it.

Structuralism and Chomsky's transformational-generative grammar are similar in how they apply general principles to define linguistics. Through such a commonality in principle, both schools of linguistics support Kuhn's thoughts that older and new paradigms are related, where the latter develops from the former. Notably, both schools of linguistics support Kuhn's idea that old terms and concepts tend to fall into new relationships once incorporated into a new paradigm. For example, Östman et al. (2007) demonstrated how general principles unite structuralism and other previous schools of linguistics. However, according to Östman et al. (2007), various linguists interpreted the same principles differently depending on context and the period since the original structuralism was adopted. Applying the same principles but interpret structuralism differently explains Kuhn's point that new schools of linguistics seldom employed elements borrowed from previous paradigms. Instead, "...old terms, concepts, and experiments fall into a new relationship one with the other" within the new paradigm (p. 149). This explains why structuralism supports the idea of studying various languages as systems.

While structuralism adequately supports Kuhn's arguments and observations, the evolution of Chomsky's Standard Theory in the mid-1960s offers a far much better explanation. In this case, the distinction of the specific models shows the connection between old and new paradigms. The Standard Theory by Chomsky presents a significant improvement of the original or early Transformational Generative Grammar. For example, 
the Standard Theory introduced a clear distinction between performance and competence of an ideal engagement between the speaker and the listener of a particular language. On the same note, the Standard Theory presents what Kuhn considered an old paradigm extension by introducing a clear distinction between the deep structure and surface structure in a particular sentence.

It is worth noting how morphology is a valuable concept that can help explain Kuhn's arguments. In particular, it is essential to address how morphing of languages or paradigms tends to incorporate much of the vocabulary and apparatus from older versions. As such, Kuhn's argument is agreeable based on how new words emerge from new ones through morphology. In particular, the process that brings the point that Kuhn refers to "conceptual and manipulative' means of incorporating old vocabulary and apparatus to form new paradigms. As the study by Bagha (2011) demonstrates, generative semantics by other linguists (John Rose and George Lakoff) stood mainly in opposition to Chomsky's transformational generative grammar. This is a clear indication of Kuhn's argument that new paradigms seldom use the borrowed elements traditionally. Instead, other linguists developed the generative semantic model from Chomsky's work. As such, proponents of linguistic semantics were keen on creating a more accommodative model beyond Chomsky's interpretation of grammar as deep structures. Consequently, they accommodate a more complex underlying platform for explaining a higher level of synonymy that Chomsky could not address.

In the same vein, the empirical evidence by Bagha (2011) demonstrates how generative semantics is unique in how it directly addresses or accounts for meaning without syntactic structure. As such, according to Chomsky, generative semantics begins with a deep structure that is also pragmatic to some extent. On that note, semantic linguists account for all possible cases in terms of the resulting intuitive structure. However, Kuhn's ideas become evident when transformations in a particular language define the form of a specific sentence. For example, through a deep structure in a language, a combination of semantic features and structures, as well as presuppositions, undergoes transformations to yield or form surface structures ultimately as initially described by Chomsky as part of the original school of linguistics. From the evidence above, it is clear that Chomsky facilitated the development and transformation of a newer yet related generative model. As such, the original generative grammar model underwent a series of modifications and adjustments to improve it and make it relevant based on the changes in linguistics. Therefore, based on Kuhn's thoughts that new paradigms are born from old ones, a comparison of the transformations can help understand linguistics.

\section{Conclusion}

In summary, existing linguistic theories support the argument by Kuhn that new paradigms are created from old ones. In particular, there is enough empirical evidence to show the link between functionalism and structuralism linguistic schools of thought that were popular in the $19^{\text {th }}$ and early- $20^{\text {th }}$ Centuries, respectively. However, based on the existing literature, the degree of agreement differs with time in agreement with Kuhn's (1970) argument. Scholars are reluctant to accept and apply the same concepts, terms, and experiments that defined previous schools of thought. According to the existing literature, generative grammar, being newer than functionalism and structuralism, offers the best school of thought for linguists. The main advantage of generative grammar and specific adjustment is how improvements have been achieved since 1965 to accommodate new ideas and address previous concerns and issues in linguistics. As such, the original generative grammar model underwent a series of transformations and adjustments to improve it and make it relevant based on the changes in linguistics. Considering Kuhn's (1970) original argument, it is still acceptable that new paradigms are born from old ones. In other words, the model became a foundational school of linguistics to create far much better models; for example, the Extended Standard Theory or the more improved Revised Standard Theory. In the same vein, Chomsky's linguistic school defends Kuhn's point regarding how new paradigms rarely apply the borrowed items such as concepts, terms, and methods. Instead, the whole idea behind new paradigms is to address the shortcomings of old paradigms by taking a different perspective.

Notably, the current study presents a genuine concern by Kuhn (1970) that new paradigms associated with linguistic schools of thought arise from previous ones. Therefore, they "...ordinarily incorporate much of the vocabulary and apparatus, both conceptual and manipulative," that traditional paradigms had previously applied (p. 149). However, according to Kuhn (1970), linguistics rarely harness elements conventionally borrowed from previous paradigms since they prefer achieving as much originality and novelty as possible. As such, the current study supports the views presented by Kuhn that new linguistic paradigms arise from previous or old concepts and terms that fall into a new relationship one with the other. According to the findings, there is a close link between schools of linguistics that have continued to define the world of linguists up to date. 


\section{References}

Adetuyi, C. A., \& Fidelis, O. O. (2015). Key concepts in transformational generative grammar. International Journal of Education and Evaluation, 1, 51-58.

Al Umman, K. Z. (2015). Ferdinand De Saussure: Structuralism and his role in modern linguistics. LISANUDHAD, 2(1), 1-19.

Alduais, A. M. (2015). A Brief Account of the Base Component of Transformational Generative Grammar. International Journal of Indian Psychology, 3(1). https://doi.org/10.25215/0301.073

Al-Horais, N. (2013). The Minimalist Program and its New Insight to the Concept of Universal Grammar. Journal of Universal Language, 14(2), 79-112. https://doi.org/10.22425/jul.2013.14.2.79

Almurashi, W. A. (2016). An introduction to Halliday's systemic functional linguistics. Journal for the study of English Linguistics, 4(1), 70-80. https://doi.org/10.5296/jsel.v4i1.9423

Andreu, J. F., \& Gallego, Á. J. (2009). Introduction. The Minimalist Program and the concept of Universal Grammar. Catalan Journal of linguistics, 8, 7-15. https://doi.org/10.5565/rev/catjl.139

Aslanova, K. (2019). Cognitive linguistics in the paradigms of linguistic functionalism and integral concepts of consciousness. Интернаука, (37), 70-71.

Bagha, K. N. (2011). Generative Semantics. English Language Learning, 4(3), 223-231. https://doi.org/10.5539/elt.v4n3p223

Bates, E., Thal, D., \& MacWhinney, B. R. I. A. N. (1991). A functionalist approach to language and its implications for assessment and intervention. In Gallagher, T. M. (Ed.), Pragmatics of Language (pp. 133-161). Springer, Boston, MA. https://doi.org/10.1007/978-1-4899-7156-2_5

Brekle, H. E., \& Luelsdorff, P. (1975). Notes on Chomsky's extended standard version. Foundations of Language, 12(3), 367-382.

Broekhuis, H., \& Woolford, E. (2013). Minimalism and optimality theory. In M. Den Dikken (Ed.), The Cambridge handbook of generative syntax (pp. 122-161). Cambridge: Cambridge University Press. https://doi.org/10.1017/CBO9780511804571.008

Butler, C. (2006). Functionalist Theories of Language. In Keith Brown (Ed.), Encyclopedia of Language \& Linguistics (pp. 696-704). The University of Huddersfield. https://doi.org/10.1016/B0-08-044854-2/04771-4

Canagarajah, S. (2018). Translingual practice as spatial repertoires: Expanding the paradigm beyond structuralist orientations. Applied Linguistics, 39(1), 31-54. https://doi.org/10.1093/applin/amx041

Chomsky, N. (1965). Aspects of the Theory of Syntax. MIT press. https://doi.org/10.21236/AD0616323

Christie, F. (2004). Systemic functional linguistics and a theory of language in education. Ilha do DesterroA Journal of English Language, Literatures in English and Cultural Studies, (46), 13-40.

Davies, W. D., \& Dubinsky, S. (2004). Revised Extended Standard Theory: Chomsky and Lasnik's "Filters and Control." In W. D. Davies \& S. Dubinsky (Eds.), The Grammar of Raising and Control. https://doi.org/10.1002/9780470755693.ch7

Epçaçan, C. (2014). Functional linguistics as for linguistic applications in Turkish language teaching. Procedia-Social and Behavioral Sciences, 116, 5063-5069. https://doi.org/10.1016/j.sbspro.2014.01.1074

Gastaldi, J., \& Pellissier, L. (2020). The Logic of Language: from the Distributional to the Structuralist Hypothesis through Types and Interaction.

Ghosh, S. (2016). Ferdinand De Saussure and the Development of Structuralism. International Journal of Sociology and Social Anthropology (IJSSA), 1(1), 59-64.

Healy, A. F., \& Levitt, A. G. (1978). The relative accessibility of semantic and deep-structure syntactic concepts. Memory \& Cognition, 6(5), 518-526. https://doi.org/10.3758/BF03198240

Hussein, B. A. S., \& Abushihab, I. (2014). A critical review of Ferdinand de Saussure's linguistic theory. Studies in Literature and Language, 8(1), 57-61.

Johnson, D., \& Lappin, S. (1997). A critique of the minimalist program. Linguistics and Philosophy, 20, 273-333. https://doi.org/10.1023/A:1005328611460

Kuhn, T. S. (1970). The structure of scientific revolutions. University of Chicago Press. 
Langendoen, D. T. (1978). Review of Essays on Form and Interpretation, by Noam Chomsky. Journal of Philosophy, 78(5), 270-279. https://doi.org/10.2307/2025966

Moghaddas, B., \& Dekhnich, O. V. (2015). The philosophy of structuralism in language and linguistics. https://doi.org/10.18413/2313-8912-2015-1-4-24-29

Muhammadi, T. A. (2016). Saussurian Structuralism in Linguistics. Journal of Literature, Languages and Linguistics, 20, 27-31.

Nilsen, D. L. (1987). Nine types of transformations: Is linguistics finally becoming meaningful? Language Sciences, 9(2), 243-252. https://doi.org/10.1016/S0388-0001(87)80023-2

Östman, J. O., Verschueren, J., \& Versluys, E. (Eds.). (2007). Handbook of pragmatics (Vol. 11). John Benjamins Publishing. https://doi.org/10.1075/hop.11

Qi, X. (2014). Globalized knowledge flows and Chinese social theory. Routledge. https://doi.org/10.4324/9781315882710

\section{Copyrights}

Copyright for this article is retained by the author(s), with first publication rights granted to the journal.

This is an open-access article distributed under the terms and conditions of the Creative Commons Attribution license (http://creativecommons.org/licenses/by/4.0/). 